\title{
Intra- and interspecific diversity analyses in the genus Eremurus in Iran using genotyping-by- sequencing reveal geographic population structure
}

\author{
Hanieh Hadizadeh ${ }^{1}$, Bochra A. Bahri' ${ }^{2,3,5}$, Peng Qi ${ }^{3}$, H. Dayton Wilde ${ }^{4}$ and Katrien M. Devos ${ }^{3}$
}

\begin{abstract}
Eremurus species, better known as 'Foxtail Lily' or 'Desert Candle', are important worldwide in landscaping and the cutflower industry. One of the centers of highest diversity of the genus Eremurus is Iran, which has seven species. However, little is known about the genetic diversity within the genus Eremurus. With the advent of genotyping-bysequencing (GBS), it is possible to develop and employ single nucleotide polymorphism (SNP) markers in a costefficient manner in any species, regardless of its ploidy level, genome size or availability of a reference genome. Population structure and phylogeographic analyses of the genus Eremurus in Iran using a minimum of 3002 SNP markers identified either at the genus level or at the species level from GBS data showed longitudinal geographic structuring at the country scale for the genus and for the species E. spectabilis and E. luteus, and at the regional scale for $E$. olgae. Our analyses furthermore showed a close genetic relatedness between $E$. olgae and E. stenophyllus to the extent that they should be considered subspecies within an E. olgae/stenophyllus species complex. Their close genetic relatedness may explain why crosses between these two (sub)species have been found in the wild and are exploited extensively as ornamentals. Last, current species identification, while robust, relies on flower morphology. A subset of seven SNPs with species-specific (private) alleles were selected that differentiate the seven Eremurus species. The markers will be especially useful for cultivar protection and in hybrid production, where true hybrids could be identified at the seedling stage.
\end{abstract}

\section{Introduction}

Eremurus, the largest genus in the Asphodelaceae, is comprised of some 45 species of herbaceous perennial plants that are native to central Asia and Caucasia ${ }^{1}$. Eremurus species are important commercially as ornamental plants for landscaping and cut-flower markets ${ }^{2}$. Due to their large and colorful floral spikes, Eremurus species are known in the international horticulture trade as "Foxtail Lily" or "Desert Candle". In addition to their ornamental

Correspondence: Katrien M. Devos (kdevos@uga.edu)

'Department of Horticulture, Faculty of Agriculture, Tarbiat Modares University, Tehran, Iran

${ }^{2}$ Laboratory of Bioaggressors and Integrated Protection in Agriculture, The National Agronomic Institute of Tunisia, University of Carthage, 1082 Tunis, Tunisia

Full list of author information is available at the end of the article.

These authors contributed equally: Hanieh Hadizadeh, Bochra A. Bahri value, Eremurus species have been used in traditional medicine and are potential sources for anti-inflammatory, antibacterial, and antiprotozoal drugs ${ }^{3-5}$. Other Eremurus products, such as bio-oil ${ }^{6}$ and adhesives ${ }^{7}$, have industrial applications.

Interspecific breeding of Eremurus species has been conducted for floral color and longevity, resulting in popular hybrids such as Eremurus $\times$ isabellinus (E. stenophyllus $\times$ E. olgae). A better understanding of the genetic variation within and among Eremurus species would facilitate breeding for ornamental traits and other properties. Naderi Safar and colleagues ${ }^{8}$ used genetic variation obtained by amplicon sequencing of the plastid trnL-F and nuclear rDNA ITS regions to conduct a molecular phylogenetic study of three Asphodelaceae genera, including Eremurus. This study showed that Eremurus

\section{(c) The Author(s) 2020}

(c) (i) Open Access This article is licensed under a Creative Commons Attribution 4.0 International License, which permits use, sharing, adaptation, distribution and reproduction cc) in any medium or format, as long as you give appropriate credit to the original author(s) and the source, provide a link to the Creative Commons license, and indicate if changes were made. The images or other third party material in this article are included in the article's Creative Commons license, unless indicated otherwise in a credit line to the material. If material is not included in the article's Creative Commons license and your intended use is not permitted by statutory regulation or exceeds the permitted use, you will need to obtain permission directly from the copyright holder. To view a copy of this license, visit http://creativecommons.org/licenses/by/4.0/. 
species grouped into the paraphyletic subgenus Henningia and the monophyletic subgenus Eremurus. However, information on the genetic diversity within Eremurus species is lacking. Recent developments in next generation sequencing technologies have enabled the detection of single nucleotide polymorphism (SNP) markers at the whole genome level in non-model species, including those that lack a sequenced genome, using reduced representation sequencing ${ }^{9-11}$. These approaches have not yet been applied to identify SNP markers across species within an angiosperm genus comprised of species with very large genomes $(>8 \mathrm{~Gb})$ and no reference genome. Both diploid (E. chinensis) and tetraploid (E. anisopterus) Eremurus species have been identified by karyotype analysis with $2 n$ chromosome counts of 14 and 28 , respectively $^{12,13}$. Flow cytometry of the diploid E. stenophyllus $(2 n=2 x=14)$ determined that it has a large $2 \mathrm{C}$ genome size of 16.2 gigabases $(1 \mathrm{C}=8.1 \mathrm{~Gb})$ and a $\mathrm{GC}$ content of $41.3 \%{ }^{14}$.

Iran is the third largest diversity center of the genus Eremurus, after the Soviet Union and Afghanistan ${ }^{15}$. There are seven Eremurus species and three subspecies found in Iran, with the greatest species diversity located in the northeastern part of the country. Eremurus stenophyllus (Boiss. \& Buhse) Baker subsp. stenophyllus is endemic to Iran and E. kopet-daghensis Karrer is subendemic $^{15}$. Eremurus stenophyllus subsp. stenophyllus and E. spectabilis M. Bieb subsp. subalbiflorus are recognized as endangered and in need of conservation ${ }^{16}$. The other Iranian species/subspecies are E. spectabilis subsp. spectabilis, E. persicus (Jaub. \& Spach) Boiss., E. olgae Regel, E. luteus Baker, and E. inderiensis (M. Bieb.) Regel. Hybrids between E. olgae and E. stenophyllus subsp. stenophyllus have been observed in the wild and are identified as E. $x$ albocitrinus Baker. Eremurus species are generally insectpollinated, although self-fertilization is possible and wind dispersal of pollen has been observed in desert habitats where pollinator activity is unreliable ${ }^{17,18}$.

In this study, we investigated the interspecific and intraspecific diversity in Eremurus spp. germplasm from Iran using SNP markers identified through genotypingby-sequencing $(\mathrm{GBS})^{10}$ to determine phylogenetic relationships and investigate correlations between the genetic diversity, morphological diversity and geographic origin. In addition to the biological significance of our research, this is the first report of the use of GBS on species of the Asphodelaceae, none of which have been sequenced to date, the first use of GBS on an angiosperm species with a genome size $(1 \mathrm{C})$ larger than $8 \mathrm{~Gb}$ and no reference genome, and one of the few applications of GBS to plants of ornamental interest. Furthermore, we demonstrate the use of GBS to study intraspecific variation as well as interspecific variation in Eremurus spp. using different SNP-calling protocols on the same dataset.

\section{Results}

Genetic analyses across species within the genus Eremurus SNP markers identified by GBS across Eremurus species

To analyze diversity in Eremurus at the genus level, a reference was assembled from GBS reads ('GBS reference') across 96 accessions belonging to seven Eremurus species collected across Iran (Supplementary Table S1; Supplementary Fig. S1). Because the reference building was carried out across species, we required each reference tag to be present in only two accessions in order to be included in the reference. The threshold we typically use for within species reference building is presence in at least $50 \%$ of the samples. The assembled GBS reference consisted of 201,099 tags. We obtained a total of 12,535 SNP markers across the 96 samples after alignment of the reads from each accession to the GBS reference and SNP calling, removal of adjacent SNPs (multiple side-by-side SNPs are sometimes caused by misalignment of reads) and filtering for biallelic SNPs, SNPs with a quality depth $(\mathrm{QD}) \geq 10$, and SNPs with $<50 \%$ of missing data. Six accessions were removed from the analysis because they had $<600,000$ reads. An additional two samples with $>1 \mathrm{M}$ reads had $>75 \%$ missing data and were also removed. The average number of reads for the remaining 88 accessions was 1.67 million $(\mathrm{M})$, with minimum and maximum read numbers of $0.72 \mathrm{M}$ and $11.43 \mathrm{M}$, respectively. We then decreased the missing data threshold for SNPs from 50 to $30 \%$, and removed SNPs with a minor allele frequency $\leq 5 \%$. The final number of SNPs used for the diversity analyses across the seven Eremurus species was 3002. A SNP resampling analysis showed that a subset of 1000 randomly selected SNPs had the same power to distinguish all multilocus genotypes as the full set of 3002 SNPs, indicating that our SNP set was adequate to determine the diversity between Eremurus species (Supplementary Fig. S2). The SNP markers, and the sequence of the corresponding GBS reads, are given in Supplementary Table S2. The genotypic scores for the 3002 SNP markers in each of the 88 accessions are given in Supplementary Table S3.

\section{Population structure analysis}

The most likely number of subpopulations was determined by Structure Harvester ${ }^{19}$ (Delta $K$ value) to be $K=$ 5, after running STRUCTURE ${ }^{20}$ with $K=1$ to $K=10$ (Supplementary Fig. S3). The subpopulation division was largely by species (Fig. 1a). Eremurus inderiensis, E. luteus, E. persicus, and E. spectabilis each formed a single subpopulation, while E. olgae and E. stenophyllus grouped together. At $K=6$ and when considering majority ( $\geq 50 \%$ ) membership to a single subpopulation, all $E$. olgae accessions and two (25\%) E. stenophyllus accessions formed one group, while the remaining E. stenophyllus accessions (75\%) formed a second group (Supplementary 


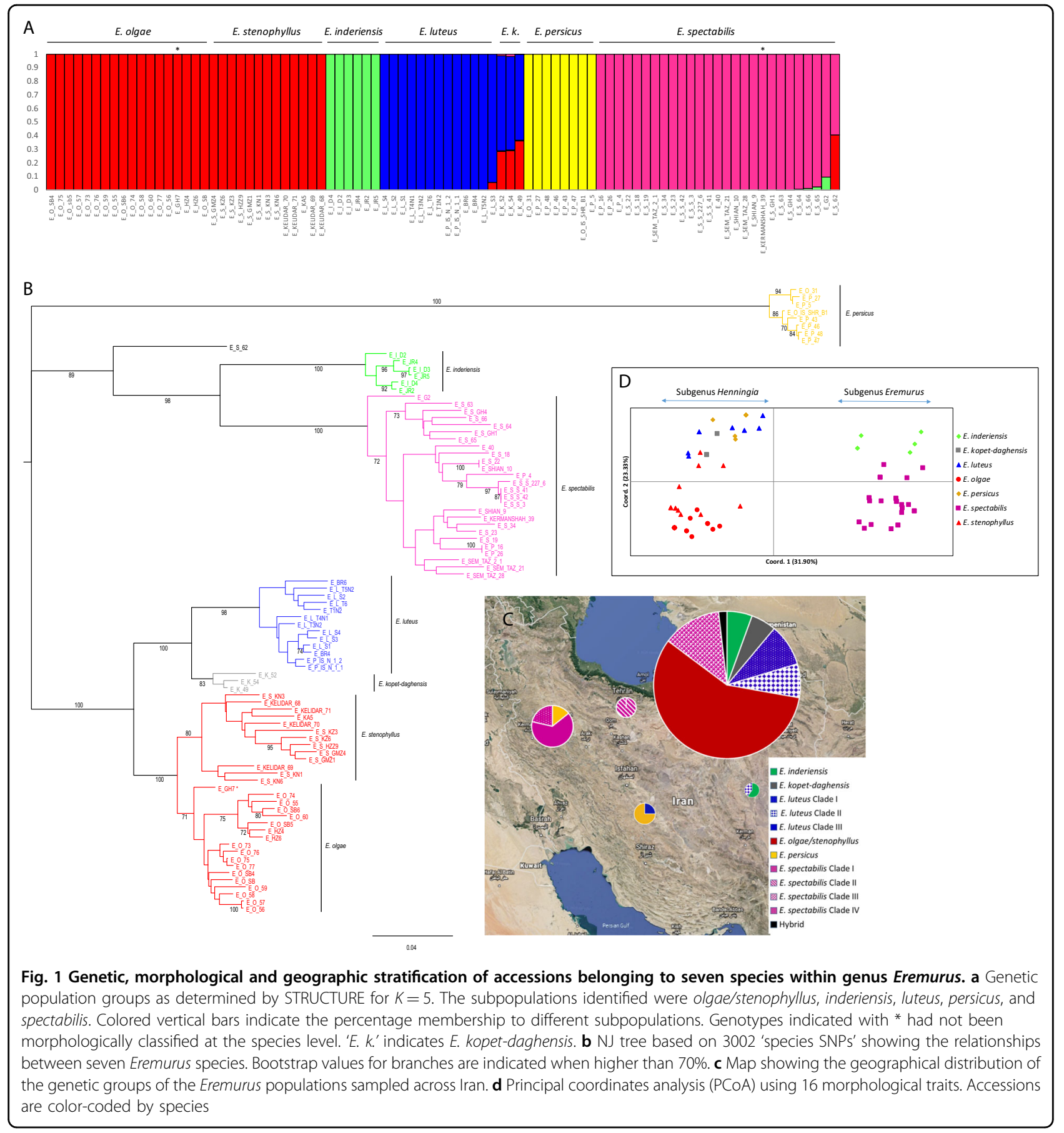

Fig. S4). However, 39\% of the E. olgae accessions and all of the E. stenophyllus accessions that belonged to the 'olgae/ stenophyllus' subpopulation at $K=5$ were admixed ( $\leq 90 \%$ membership to a single subpopulation) at $K=6$. At $K=5$, all three $E$. kopet-daghensis individuals were admixed with approximately $2 / 3$ membership to subpopulation 'luteus' and 1/3 membership to subpopulation 'olgae/stenophyllus' (Fig. 1a). The only other line that was admixed at $K=5$ was E_S_62, which had 59\% membership to subpopulation 'spectabilis' and $41 \%$ to 'olgae/stenophyllus'. E_S_62, which had been identified morphologically as E. spectabilis, had a considerably higher number of heterozygous SNPs (31.1\%) compared with the other Eremurus accessions $(<10 \%)$.

\section{Phylogeographic analyses within the genus Eremurus}

Neighbor Joining (NJ) and Unweighted Pair Group Method with Arithmetic mean (UPGMA) analyses, 


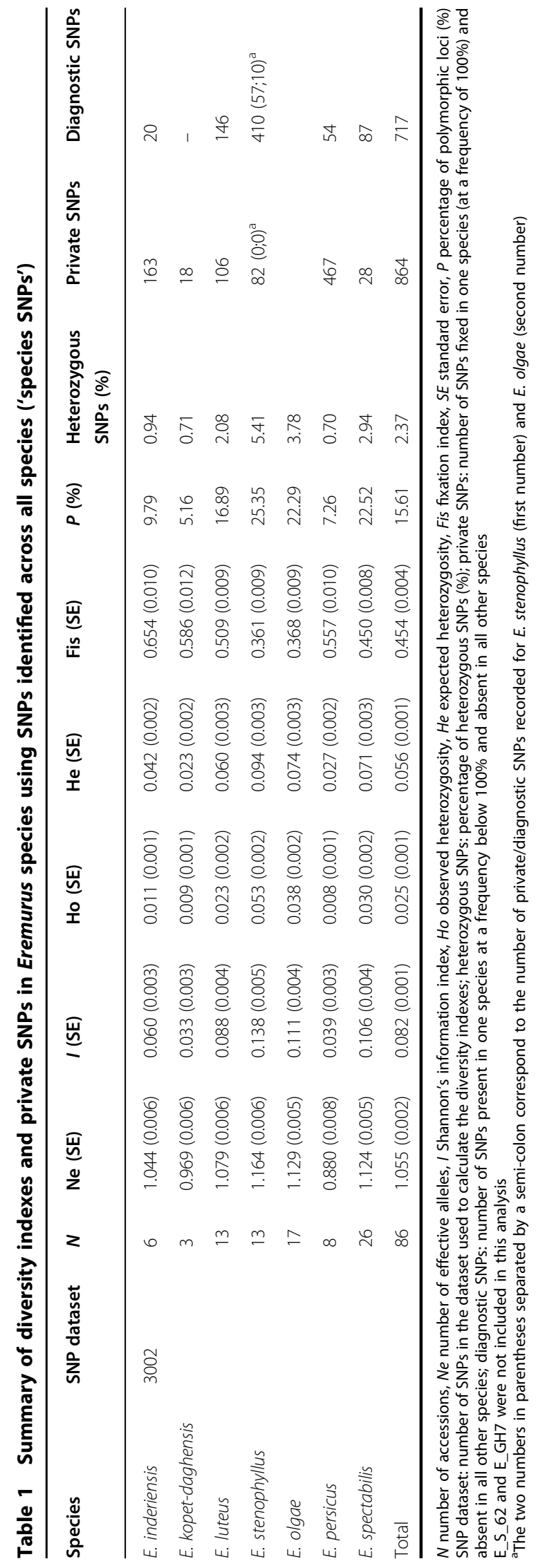

carried out with the set of 3002 'species SNPs', separated the seven species in very strongly supported clades (bootstrap values $\geq 98 \%$ ) (Fig. 1b and Supplementary Fig. S5). The seven species' clades were organized into three superclades. Interrelationships between the superclades were unresolved in the NJ tree (Fig. 1b), but the UPGMA tree topology suggested that superclades 1 and 2 were most closely related (Supplementary Fig. S5). Superclade 1 comprised E. olgae, E. stenophyllus, E. luteus, and E. kopet-daghensis. E. olgae was sister to E. stenophyllus, and $E$. luteus was sister to E. kopet-daghensis. Superclade 2 comprised two sister clades corresponding to $E$. inderiensis and E. spectabilis, and E. persicus formed superclade 3. The pairwise Nei's genetic distances between the seven Eremurus species revealed E. olgae and E. stenophylus as the most closely related species $(\mathrm{Nei}=0.059$; $\mathrm{Fst}=0.217$; Supplementary Table S4). With the exception of a few branches, relationships between accessions within species had low bootstrap values (Fig. 1b).

The genus Eremurus in Iran was geographically structured according to an East-West transect. Overall, a Mantel test revealed a significant correlation between genetic and geographic distances $(\mathrm{Rxy}=0.439 ; P=$ 0.001). Within subgenus Eremurus (Supplementary Table S1), E. spectabilis was the dominant species in the western part of Iran, while E. inderiensis was only present in the eastern part of Iran (Fig. 1c). All species sampled within subgenus Henningia originated from the eastern part of Iran except E. persicus, which was only present in the west and center of Iran.

\section{Private alleles that can be used for species identification}

Overall, high genetic differentiation $(F s t=0.832)$ and a low level of gene flow $\left(N_{\mathrm{m}}=0.579\right)$ were observed between the seven Eremurus species leading to the identification of a total of 864 private alleles (alleles that are unique to a single species and present in that species at a frequency of 100\%) and 717 diagnostic alleles (alleles that are unique to a single species but present in that species at a frequency $<100 \%$ ) (Table 1$)$. This represents $26.3 \%$ of all alleles. The SNP markers with private alleles (Supplementary Table S2) can be used to classify Eremurus at the species level. The highest number of private alleles (467) was found in E. persicus, the species with the highest Nei's genetic distances from the other Eremurus species analyzed (Nei's distances $\geq 0.626$ ) (Supplementary Table S4). No private alleles were identified for E. olgae or E. stenophyllus, but both species did carry diagnostic alleles. The highest frequency of any diagnostic allele in E. stenophyllus was $88.5 \%$ while in E. olgae, the highest frequency was $61.8 \%$. A total of 82 and 410 alleles were private and diagnostic, respectively, for the E. olgae/E. stenophyllus complex. The number of private and diagnostic alleles per subpopulation is given in Table 1 . 
SNPs with private alleles are indicated in Supplementary Table S2.

\section{Morphological analyses across species within the genus Eremurus}

Tepal color was the most polymorphic trait evaluated across the Eremurus species with seven characters recorded and a Shannon diversity index $H^{\prime}$ of 1.568 . Rhizome diameter was the least powerful trait to differentiate the accessions morphologically with two characters recorded and an $H^{\prime}$ of 0.251 (Supplementary Table S5). Four morphological traits, tepal color, tepal nerve, tepal tip, and flower shape, were singly able to distinguish the two subgenera, Eremurus and Henningia, as defined by Wendelbo ${ }^{15}$ (Supplementary Table S6). In addition, tepal color, tepal tip and flower shape used in combination were able to differentiate the seven species. Overall, species were highly differentiated morphologically $(P<$ 0.001 ); the morphological variability among species accounted for $70 \%$ of the total variability while the variability within species accounted for only 30\% (Supplementary Table S7). The two most morphologically diverse species were E. stenophyllus and E. spectabilis with 10 and 19 morphotypes, and Shannon diversity indexes of 0.316 and 0.226 , respectively (Table 2). E. kopet-daghensis was the least diverse with two morphotypes and a Shannon diversity index of 0.040 .

Eremurus spectabilis, E. inderiensis, E. kopet-daghensis, and $E$. luteus each had one private morphological character, campanulate flower shape (E. spectabilis), tubular flower shape (E. inderiensis), pale pink tepals (E. kopetdaghensis), and pale yellow tepals (E. luteus). White, yellow, and orange tepal colors were diagnostic for E. stenophyllus. No variation was observed within species for tepal nerve, tepal tip, flower shape, bract margin, fruit shape, or leaf margin and surface indumentum. In contrast, inflorescence length displayed variation within all Eremurus species (Supplementary Table S6).

Overall, 55 morphotypes (matrices consisting of all 16 morphological characters) were recorded and all of them were specific to one of the studied species (Supplementary Table S8). Specific morphotypes were also recorded for each clade of E. spectabilis, E. olgae, E. stenophyllus, and $E$. luteus except $E$. luteus Clade II, where none of the five morphotypes observed were unique to Clade II (Supplementary Table S9). One trait out of the 16 evaluated (tepal color) was able to differentiate E. stenophyllus Clade I (yellow tepal color) from the rest of the E. stenophyllus accessions.

When accessions were color-coded according to their genetic affiliation, the PCoA based on the 16 morphological traits showed a similar clustering of accessions to that obtained using the 3002 SNPs (Fig. 1d). The first coordinate of the PCoA explained $31.9 \%$ of the genetic variability and separated subgenus Eremurus from subgenus Henningia. Three traits, tepal color, tepal nerve, and tepal tip, were the main contributors $(56 \%)$ to the variation explained by axis 1 (Supplementary Table S10). The second coordinate, explaining $23.3 \%$ of the genetic variability, distinguished $E$. inderiensis from $E$. spectabilis within subgenus Eremurus. The second coordinate also separated the species within subgenus Henningia into three groups represented by E. olgae, E. stenophyllus and the rest (E. luteus, E. persicus, E. kopet-daghensis) (Fig. 1d). The traits that were most highly correlated with axis 2 were stem length and leaf margin indumentum (35\% contribution; Supplementary Table S10). The third coordinate explained $9.9 \%$ of the variation and distinguished E. persicus from E. luteus and E. kopetdaghensis. In addition, significant correlations between morphological and genetic distances across species were revealed $(\mathrm{Rxy}=0.636, P=0.010)$.

Table 2 Summary of morphological diversity across species within the genus Eremurus

\begin{tabular}{llllllll}
\hline Species & Subgenus & Section & $\boldsymbol{N}$ & $\boldsymbol{H}^{\prime}(\mathrm{SE})$ & Morphotype & Private character & Diagnostic character \\
\hline E. spectabilis & Eremurus & Eremurus & 25 & $0.226(0.078)$ & 19 & 1 & 0 \\
E. inderiensis & Eremurus & Ammolirion & 6 & $0.186(0.073)$ & 5 & 1 & 0 \\
E. kopet-daghensis & Henningia & Henningia & 3 & $0.040(0.040)$ & 2 & 1 & 0 \\
E. luteus & Henningia & Henningia & 13 & $0.168(0.061)$ & 7 & 1 & 0 \\
E. stenophyllus & Henningia & Henningia & 13 & $0.316(0.084)$ & 10 & 0 & 3 \\
E. olgae & Henningia & Henningia & 17 & $0.125(0.054)$ & 8 & 0 & 0 \\
E. persicus & Henningia & Henningia & 8 & $0.071(0.038)$ & 4 & 0 & 0 \\
Total & & & 85 & $0.162(0.025)$ & 55 & 4 & 3 \\
\hline
\end{tabular}

$N$ no. of accessions, $H^{\prime}$ Shannon-Weiner diversity index $=-\sum p_{i} \ln \left(p_{i}\right), S E$ standard error

Morphotype: number of different combinations of morphological characters; private character: character fixed in one species at a frequency of $100 \%$ and absent in all other species; diagnostic character: character present in one species at a frequency below $100 \%$ and absent in all other species

E_KERMANSHAH_39, E_S_62, and E_GH7 were not included in this analysis 
Table 3 Summary of diversity indexes and private SNPs in Eremurus species using SNPs identified within subpopulations ('subpopulation SNPs')

\begin{tabular}{llllllllll}
\hline Species & SNP dataset & $\boldsymbol{N}$ & Ne (SE) & $\boldsymbol{I}(\mathrm{SE})$ & Ho (SE) & He (SE) & Fis (SE) & $P$ (\%) & Heterozygous SNPs (\%) \\
\hline E. luteus & 6131 & 13 & $1.810(0.002)$ & $0.632(0.001)$ & $0.204(0.002)$ & $0.441(0.001)$ & $0.552(0.003)$ & 100.00 & 19.46 \\
E. stenophyllus & 5281 & 13 & $1.559(0.004)$ & $0.501(0.002)$ & $0.260(0.002)$ & $0.334(0.002)$ & $0.190(0.005)$ & 94.49 & 25.19 \\
E. olgae & & 17 & $1.345(0.005)$ & $0.322(0.004)$ & $0.145(0.002)$ & $0.208(0.003)$ & $0.225(0.005)$ & 74.82 & 14.44 \\
E. spectabilis & 4175 & 26 & $1.701(0.004)$ & $0.587(0.001)$ & $0.179(0.002)$ & $0.401(0.001)$ & $0.587(0.004)$ & 100.00 & 16.96 \\
\hline
\end{tabular}

$N$ number of accessions, Ne number of effective alleles, I Shannon's information index, Ho observed heterozygosity, He expected heterozygosity, Fis fixation index, SE standard error, $P$ percentage of polymorphic loci (\%)

SNP dataset: number of SNPs in the dataset used to calculate the diversity indexes; private SNPs: number of SNPs fixed in one species (at a frequency of 100\%) and absent in all other species; diagnostic SNPs: number of SNPs present in one species at a frequency below $100 \%$ and absent in all other species

E_S_62 and E_GH7 were not included in this analysis

\section{Genetic analyses within genetic subpopulations in the genus Eremurus \\ SNP markers identified within Eremurus subpopulations}

To resolve intraspecies relationships, GBS data for the three largest subpopulation groups identified by STRUCTURE at $K=5$ and by phylogenetic analyses ( $E$. olgae/stenophyllus, E. spectabilis, and E. luteus) were reanalyzed within each subpopulation to identify biallelic SNPs with a QD value $\geq 10$, an allele frequency $\geq 10 \%$ and $\leq 15 \%$ missing data. Adjacent SNPs were also removed. A total of 22,934 reference tags were obtained for subpopulation 'spectabilis', 27,258 for subpopulation 'olgae/ stenophyllus' and 24,735 for subpopulation 'luteus'. The highest percentage of unique reference tags was found in subpopulation 'spectabilis' (65\%), and the highest percentage of shared tags (23\%) was observed between subpopulations 'olgae/stenophyllus' and 'luteus'. This concurs with E. olgae, E. stenophyllus, and E. luteus belonging to subgenus Henningia, and E. spectabilis belonging to subgenus Eremurus. Some 21\% of the tags were shared between all three subpopulations (Supplementary Table S11). Using the generated GBS references in each subpopulation, we obtained 4175 SNPs for subpopulation 'spectabilis', 5281 SNPs for subpopulation 'olgae/stenophyllus' and 6131 SNPs for subpopulation 'luteus'. The majority (90.3\%) of the SNP-carrying GBS reference tags were specific to a single subpopulation, $9.0 \%$ were common to two subpopulations, and $0.7 \%$ were shared between three subpopulations. The lower number of shared tags when considering only the SNP-carrying tags used in the analyses compared with all reference tags can be explained by the fact that common reference tags are not necessarily polymorphic in all subpopulations. The SNP markers, their location and the sequence of the corresponding GBS reads for subpopulations 'spectabilis', 'olgae/stenophyllus', and 'luteus' are given in Supplementary Tables S12, S13, and S14, respectively. The genotypic scores for each SNP marker for accessions within a subpopulation are given in Supplementary Tables S15, S16, and S17.
SNPs identified within subpopulations ('subpopulation SNPs') showed higher diversity indexes compared with SNPs identified across all species ('species SNPs') for each of the largest population groups investigated. Shannon's information index $I$ was 4.8 -fold higher on average using 'subpopulation SNPs' (Table 3) than using 'species SNPs' (Table 1). Based on the 'subpopulation SNPs', E. luteus had the highest diversity among the four species analyzed (E. luteus, E. olgae, E. stenophyllus, and E. spectabilis) with a Shannon's information index $I$ of 0.632 (Table 3). It should be noted, however, that the 'subpopulation SNPs' were different for each species, except for E. stenophyllus and E. olgae where building of the GBS reference and SNP calling was done within the subpopulation stenophyllus/ olgae. When using 'species SNPs', E. luteus presented the lowest genetic diversity $(I=0.088)$ of the four species (Table 1).

\section{Phylogeographic analyses within STRUCTURE subpopulations}

Using both larger SNP numbers and less conserved SNPs allowed most inter-accession relationships to be resolved with bootstrap values $\geq 70 \%$ (Fig. 2). Within subpopulation 'spectabilis' (Fig. 2a), four clades largely grouped accessions by geographic location. Clades I and IV were collected in the western part of Iran, while Clade II and Clade III were found in the center and eastern part of Iran, respectively (Fig. 1c).

As indicated by the phylogenetic trees obtained with both the 'species SNPs' and the 'subpopulation SNPs', subpopulation 'olgae/stenophyllus' consisted of two sister clades, one comprising E. olgae accessions and the other comprising E. stenophyllus accessions (Figs. 1b and 2b). Both species were collected from the eastern part of Iran (Fig. 1c), and no geographic patterning at the regional level was observed that separated the two species. Discrepant placement in the two analyses was found for $E$. stenophyllus accession E_S_KN3, which was phylogenetically more closely related to E. olgae than to E. stenophyllus in the phylogeny using 'subpopulation SNPs', but grouped with E. stenophyllus in the across-species 


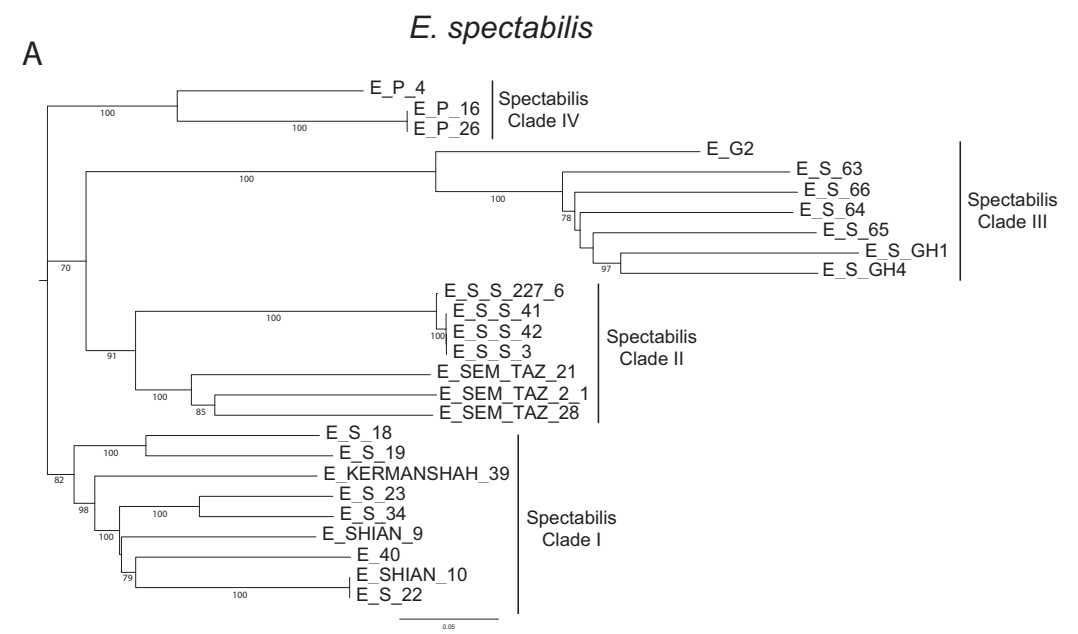

B

\section{E. olgae/E. stenophyllus}

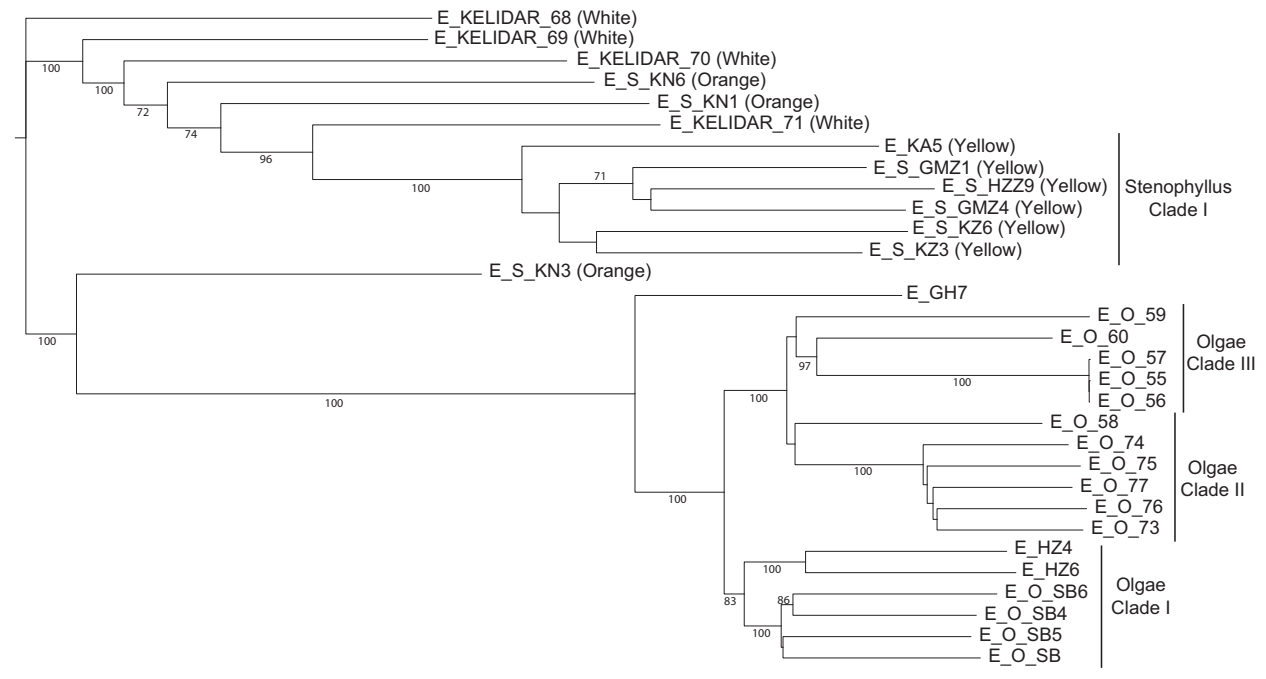

C

\section{E. luteus}

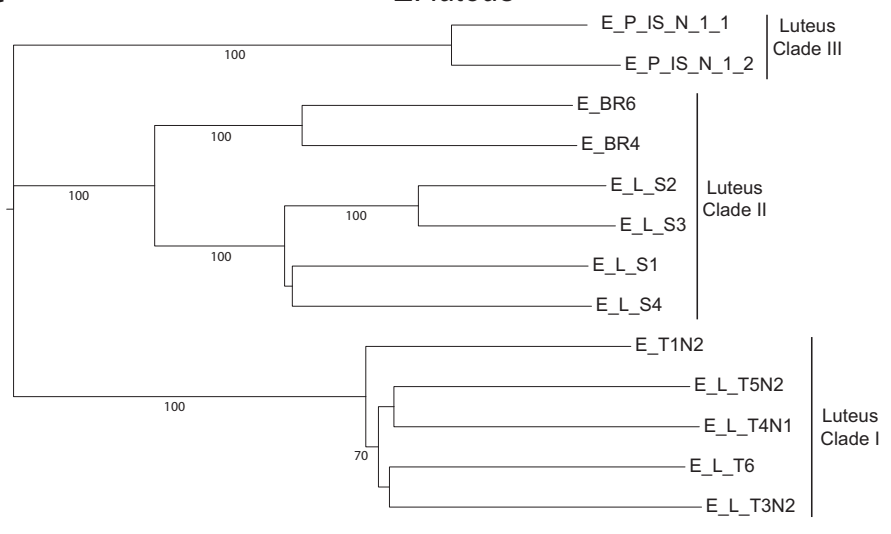

Fig. 2 Phylogenetic trees within subpopulations. Trees within a E. spectabilis, $\mathbf{b}$ the E. olgae/E. stenophyllus species complex, and $\mathbf{c} E$. luteus were generated using, respectively, 4175, 5281, and 6131 'subpopulation SNPs'. Bootstrap values for branches are indicated when higher than $70 \%$. For accessions belonging to $E$. stenophyllus, flower color is given in parenthesis after the accession name 
phylogeny and the STRUCTURE analysis at $K=6$. An analysis of Nei's genetic distance and genetic differentiation at the species level using 'species SNPs' showed that these two diversity indices were at least 3.6 (Nei's distance) and 2.4-fold (Fst) lower between E. stenophyllus and E. olgae than between any other two species (Supplementary Table S4). Eremurus stenophyllus was the only species that had flower color variants. In addition to the typical yellow color, some accessions had orange or white flowers. All E. stenophyllus accessions with yellow-colored flowers grouped into a single clade I (Fig. 2b; Supplementary Table S9), but were not geographically isolated from the rest of the E. stenophyllus accessions. Within $E$. olgae, three clades were identified. While all E. olgae species were found in eastern Iran, some geographic patterning was found at the regional scale. Clade I was present at more western longitudes, while Clades II and III were prevalent at more eastern longitudes.

Three clades with unresolved relationships were identified in E. luteus (Fig. 2c). Clade I comprised five species collected at the same location (N36.3-E59.4) in eastern Iran. Clade II, also sampled in eastern Iran, consisted of two sister subclades, one comprising four species collected at N35.7-E61.1 and the other consisting of two species collected at N32.9-E59.2. Clade III comprised two accessions collected in the center of Iran (at N33.4-E53.9).

\section{Discussion}

\section{Genotyping-by-sequencing for phylogenetic analysis across species within a genus}

Genotyping-by-sequencing has been used in a number of species without a reference genome to identify SNP markers for genetic mapping or diversity analyses, e.g., refs. ${ }^{11,21-23}$. Here, we demonstrate that the use of the methylation-sensitive restriction enzyme Pst In combination with $M s p I$ is effective even in species with a very large genome such as foxtail lily $(1 \mathrm{C}=8.1 \mathrm{~Gb})$. Furthermore, using GBS references generated either across species or within species, the same GBS reads can be used to provide markers suitable for cross-species and intraspecific applications, respectively. To generate a reduced representation genome reference from GBS reads using the UGbS-Flex pipeline, we first clustered reads within accessions, extracted consensus sequences from each cluster, and then clustered the consensus sequences across accessions ${ }^{11}$. While we typically require a consensus sequence to be present in at least $50 \%$ of the accessions in order to be included in the reference, we did not apply this criterion for the generation of the crossspecies reference. The main reason for not preselecting reference tags based on their prevalence in the set of samples was that the 'ustacks' program ${ }^{24}$ only groups sequences that fully overlap and we were concerned that the $50 \%$ threshold was too stringent, particularly because we did not know the level of divergence between the seven Eremurus species. We then used blast all-vs.-all to identify tags that had $\geq 98 \%$ homology and discarded all but one of the closely related sequences. This reference consisted of 201,099 sequences. Because we discarded SNPs with $>30 \%$ of missing data, the 3002 SNPs used in the analysis were derived from highly conserved regions in the genome and were polymorphic at the species level rather than between accessions within a species. These 3002 SNPs clustered accessions by species with bootstrap values of $\geq 98 \%$ in NJ and UPGMA trees.

As expected, however, little bootstrap support was obtained for the majority of relationships between accessions within a species. To increase the resolution at the accession level, we extracted the raw reads for the three largest subpopulations obtained with STRUCTURE, which essentially corresponded to the species E. stenophyllus/E. olgae, E. luteus, and E. spectabilis. Generation of a GBS reference and SNP calling was then carried out within each subpopulation group. For this analysis, only sequences that were present in at least $50 \%$ of the accessions within a subpopulation were included in the reference, leading to smaller reference sets. Because of limitations on the number of SNPs that could be used within the phylogenetic program 'DARwin', we removed SNPs with an allele frequency $<10 \%$ and $>15 \%$ missing data, retaining 5281 SNPs for subpopulation 'olgae/stenophyllus', 6131 SNPs for subpopulation 'luteus' and 4175 SNPs for subpopulation 'spectabilis'.

\section{Genetic relationships between and within Eremurus species}

We used STRUCTURE ${ }^{20}$, which applies a Bayesian iterative algorithm, to determine the most likely number of genetic groups and the membership of each Eremurus accession to these groups. We obtained five clusters (Fig. 1a), with no or very few admixed ( $\leq 90 \%$ membership to a single subpopulation) accessions within each cluster. E_K_49, E_K_52, and E_K_54, the only three E. kopetdaghensis accessions in our study, had $\geq 50 \%$ (but $\leq 90 \%$ ) membership to subpopulation 'luteus' and minority membership ( $>10 \%$ and $<50 \%)$ to the 'olgae/stenophyllus' subpopulation. E_S_62, an accession identified based on morphological characters as E. spectabilis, had majority membership to E. spectabilis and minority membership to subpopulation 'olgae/stenophyllus'. E. olgae and E. stenophyllus accessions fell within a single subpopulation. NJ and UPGMA analyses resolved the seven species into seven strongly supported clades. In agreement with the STRUCTURE results, the three E. kopet-daghensis accessions were sister to the E. luteus clade, and both clades were sister to the E. olgae and E. stenophyllus clades (Fig. 1b). 
In 1876, Baker divided the genus Eremurus into three subgenera, Eremurus verus, Ammolirion, and Henningia ${ }^{25}$. Wendelbo ${ }^{15}$ recognized only two genera, Eremurus, which comprised sections Eremurus and Ammolirion, and Henningia, which comprised section Henningia. The seven Eremurus species found in Iran are distributed across the three genera/sections. E. spectabilis was classified as belonging to subgenus Eremurus section Eremurus, E. inderiensis as belonging to subgenus Eremurus section Ammolirion, and E. luteus, E. olgae, E. persicus, E. stenophyllus, and E. kopet-daghensis as belonging to subgenus Henningia section Henningia. Naderi Safar and colleagues ${ }^{8}$ subsequently showed using plastid trnL-F and ribosomal internal transcribed spacer (ITS) sequences that subgenus Henningia was paraphyletic, with E. persicus placed separately from the remainder of species belonging to this subgenus. Our results largely agree with Naderi Safar et al. ${ }^{8}$ with E. luteus, E. kopet-daghensis, E. stenophyllus, and $E$. olgae being located in one superclade (Superclade 1 in Supplementary Fig. S5), while E. persicus formed a separate superclade (Superclade 3 in Supplementary Fig. S5). Furthermore, pairwise Nei's genetic distances showed that $E$. persicus was the most diverged of all Eremurus species analyzed (Supplementary Table S4), further supporting that E. persicus should be placed in a separate subgenus.

Our data also bring into question some of the current species delineations. Nei's genetic difference and the genetic differentiation between any two species is, on average, 0.441 and 0.668 , respectively. In contrast, these values are 0.059 and 0.217 when comparing E. olgae and E. stenophyllus. Furthermore, E. olgae and E. stenophyllus are inter-fertile, not geographically differentiated, and grouped in the same genetic subpopulation in a STRUCTURE analysis. We therefore recommend the use of 'olgae' and 'stenophyllus' at the subspecies level within the species complex E. olgae/stenophyllus.

\section{Phylogeography of Eremurus species in Iran}

As expected, 'subpopulation SNPs' showed higher genetic diversity than 'species SNPs' suggesting that although 'species SNPs' are more efficient for species differentiation, 'subpopulation SNPs' are more accurate for diversity evaluation within species. The SNP data obtained from both the across-species and intraspecies analyses of the GBS reads demonstrated that accessions typically group by geographic location. Geographic distances and genetic distances calculated using 'species SNPs' were significantly correlated (Rxy $=0.439, P=$ 0.001) and the population of Eremurus accessions was geographically structured along a longitudinal axis. When Mantel tests were performed within species, the results revealed significant correlations between geographic and genetic distances (based on 'subpopulation SNPs') only for
E. persicus $(\mathrm{Rxy}=0.574, P=0.020)$ and $E$. spectabilis $(\mathrm{Rxy}=0.135, P=0.05)$. Interestingly, $E$. stenophyllus, which typically has yellow flowers, was found in three color variants in the same geographic region (N36.72-E58.53). Yellow-colored accessions formed a single cluster, but the white and orange accessions did not cluster at the genetic level by flower color. This may not be too surprising considering that the color variants grow in sympatry and that foxtail lily is outcrossing.

\section{Levels of heterozygosity}

When analyzing SNP variants across species (using 'species SNPs'), the number of heterozygous loci identified within each accession was, on average, $3 \%$. SNPs were called only for loci that had a sequencing depth of at least eight reads, which was sufficient to reliably identify heterozygous $\mathrm{SNPs}^{11}$. Hence, the paucity of heterozygous loci in foxtail lily, an outcrossing species, is not caused by a lack of read depth. Most likely, the SNP loci used for the across-species analyses were highly conserved and, consequently, alleles were fixed within a species. This is supported by the high correlation $\left(r^{2}=0.96, P<0.001\right)$ between the overall diversity within a species and the percentage of heterozygous loci (Table 1). The only exception to the low occurrence of heterozygous SNPs was accession E_S_62, which had 31.1\% heterozygotes and, based on STRUCTURE, NJ and PCoA analyses, was an interspecific hybrid between E. spectabilis and E. olgae/ stenophyllus. However, no hybrids between species belonging to subgenus Eremurus and Henningia have been reported to date. Furthermore, E_S_62 had been identified morphologically as E. spectabilis and had the same morphotype as another E. spectabilis accession, E_S_64. Therefore, we deduce that the 'hybrid' status and high level of heterozygosity of E_S_62 were most likely caused by sample contamination.

When SNPs were used that were identified within subpopulations ('subpopulation SNPs'), a higher percentage of heterozygous loci (on average, 19.5\% for E. luteus, $17.0 \%$ for E. spectabilis, $14.4 \%$ for E. olgae, and $25.2 \%$ for E. stenophyllus) were identified (Table 3), commensurate with Eremurus species being predominantly outcrossing.

\section{Morphological characterization}

Of the 16 evaluated traits, tepal color was the most variable trait and was informative for subgenus differentiation according to Wendelbo ${ }^{15}$. Eremurus persicus, which should be placed in its own subgenus based on the genetic data, could be distinguished from other species in Wendelbo's subgenus Henningia by a hairy leaf surface. Although only four species of the genus Eremurus ( $E$. spectabilis, E. inderiensis, E. kopet-daghensis, and E. luteus) displayed private morphological characters, a set of three morphological traits (flower shape, tepal color, 
and tepal tip) was sufficient to differentiate the seven species, highlighting the importance of morphological characterization. Species clustering based on morphological data in the PCoA was driven largely by the few flower characteristics that are key identifiers for Eremurus species. Most vegetative characters contributed little to the PCoA axes. Consequently, species classification based on morphology could only be done unambiguously at the flowering stage. When only the eight vegetative traits measured in our study were considered, some species' morphotypes overlapped. Similar morphotypes were seen not only within subgenera, but also across subgenera, indicating that the eight vegetative traits are insufficient to differentiate accessions at the subgenus level. In contrast, all species could be identified at any stage during their life cycle using a panel of seven SNPs. Any SNP with speciesspecific (or private) alleles (indicated in Supplementary Table S2) could be used singly to unambiguously identify that species or, in the case of E. stenophyllus/E. olgae, the species complex. No private alleles were identified that uniquely identified $E$. stenophyllus or E. olgae. However, three markers diagnostic for E. stenophyllus (M0087, M0367, and M0368) each could distinguish all 17 E. stenophyllus accessions analyzed from the $13 \mathrm{E}$. olgae accessions. With the exception of three E. stenophyllus accessions that were heterozygous, all E. stenophyllus accessions were homozygous for the alternate allele, while $E$. olgae accessions were homozygous for the reference allele. Although morphological and genetic distances were highly correlated, the genetic markers presented in this work definitely represent the most accurate and rapid method to resolve species and subspecies classifications of accessions within the genus Eremurus, in particular during the vegetative growth stage. For example, E_GH7 and E_KERMANSHAH_39, two accessions that were collected at the vegetative stage and classified only at the genus level were identified as E. olgae and E. spectabilis, respectively, using SNP markers. Furthermore, the SNP markers with private (species-specific) alleles provide a rapid method for phenotyping of hybrids.

\section{Conclusions}

Our study provides the first use of GBS in an angiosperm species with a haploid genome size larger than $8 \mathrm{~Gb}$. Despite the absence of a reference genome, SNPs were successfully identified across species within the genus Eremurus as well as within Eremurus species using GBS reference tags that were assembled across all species ('species SNPs') or within species/subpopulations ('subpopulation SNPs'), respectively. Our data demonstrated longitudinal geographic stratification at the country level for the genus and for the species E. spectabilis and $E$. luteus and, at the regional scale, for $E$. olgae. While classification of species based on morphology was robust, the
SNPs provided a tool to identify species during the vegetative stage, which should be particularly useful for breeding purposes, including identification of diverse parents for crossing, hybrid identification, and cultivar protection. Furthermore, the SNPs provided important new information regarding the genetic relatedness of species within the genus Eremurus that suggests that reclassification at the subgenus and species level is in order.

\section{Materials and methods \\ Sample collection}

Leaves were collected from wild Eremurus populations in Iran during the spring and early summer of 2015 and 2016 , and stored at $-20^{\circ} \mathrm{C}$ until further use. A total of 143 genotypes belonging to seven species were collected from nine provinces. One to six individuals were sampled per location. The majority of species were identified in situ based on flower morphology. For each accessions, 16 morphological characteristics were measured (inflorescence length, stem length, leaf length, leaf number, stem diameter, rhizome number, rhizome diameter, peduncle length, tepal color, tepal nerve, tepal tip, flower shape, bract margin, fruit shape, margin of leaves indumentum, and surface of leaves indumentum) which, combined, defined an accession's morphotype. The subset of 88 genotypes that was successfully analyzed by GBS, together with their species designation based on morphological characteristics and genetic data, subgenus, geographic origin and morphotype, is presented in Supplementary Table S1. Source locations are shown in Supplementary Fig. S1.

\section{DNA extraction and genotyping}

Genomic DNA was isolated from frozen leaf tissue using a CTAB procedure ${ }^{26}$. The DNA quantity and quality were determined by Nanodrop spectrophotometry (Thermo Scientific) and agarose gel electrophoresis. Ninety-six Eremurus spp. samples that had high DNA quality and were representative of the sampled populations were chosen for GBS analysis. GBS was done as described by Qi et al. ${ }^{11}$ using the enzyme combination PstI/MspI. Briefly, 250 ng of DNA from each sample was double-digested with Pst I and MspI, and ligated to a barcoded adapter at the PstI site and a common Y-adapter at the MspI site. Unligated adaptors were removed with OMEGA Mag-bind RXNPure plus Beads. Samples were PCR-amplified separately and the individual libraries were quantified using SYBR Green. Amplicon size range for 11 samples from the high and low end of the range were verified on a Bioanalyzer (Agilent). An epMotion 5075 pipetting system was used to pool $5 \mathrm{ng}$ of each of the 96 samples. The pooled library sample was quantified by Qubit and a subsample was run on a fragment analyzer. A 
KAPA Library Quantification Kit was used to determine library concentration prior to sequencing on a NextSeq (150 cycles) SE 150 Mid Output flow cell.

\section{Generation of a GBS reference and SNP calling}

Processing of the GBS reads and generation of a GBS reference using the scripts 'ustacks' 24 and 'ASustacks' were essentially done as described in Qi et al. ${ }^{11}$. For interspecific analyses, the GBS reference was generated across all accessions within the genus Eremurus. For intraspecific analyses, the GBS reference was generated across accessions within a species. The parameters used in 'ustacks' and 'ASustacks' were '-m 2, -M 2 and -N 4'. Tags that were present in at least two accessions and at least $50 \%$ of the accessions were included in the inter- and intraspecific GBS references, respectively. If two or more tags had $\geq 98 \%$ sequence identity, only a single tag was included in the reference ${ }^{11}$.

Reads from each accession were aligned to the relevant GBS reference(s) with Bowtie $2^{27}$, and SNP calling was done using Unified Genotyper from the Genome Analysis Toolkit $(\text { GATK })^{28}$ using the work flow and scripts described in Qi et al. ${ }^{11}$. SNP filtering included removal of SNPs with three or more alleles, removal of SNPs with allele frequencies $<0.1$ and $>0.9$, and removal of adjacent SNPs. SNPs with a read depth of at least $8 \mathrm{X}$ were converted to the mapping scores $\mathrm{A}, \mathrm{B}, \mathrm{H}, \mathrm{D}(\mathrm{A}$ or $\mathrm{H})$, and $\mathrm{C}$ $(B \text { or } H)^{11}$. These scores were later converted for use in GenAlEx to the format $11(\mathrm{~A}), 22(\mathrm{~B})$, and $12(\mathrm{H})$; C and D scores were changed to missing data points $(00)$. Markers with more than $50 \%$ of missing data were removed.

\section{Identification of GBS reference tags shared between species}

Intraspecific GBS references were generated for each of the three largest subpopulation groups as determined by STRUCTURE (see below). To identify GBS reference tags that were shared between the three subpopulations analyzed, the reference tags belonging to each subpopulation were pooled and compared with one another using BLASTN. If two or more tags had $\geq 95 \%$ sequence identity, only a single tag was kept. All tags with $<95 \%$ sequence identity across the three subpopulations formed the nonredundant tag set. GBS reference tags from each population were then compared with the non-redundant tag set using BLASTN to identify tags that were unique to that population or shared between populations.

\section{Population structure analysis}

The population structure of the genotyped Eremurus spp. germplasm was determined based on the SNP set identified across all 88 genotyped accessions belonging to seven Iranian Eremurus species. Genetic subpopulations were identified using the Bayesian clustering procedure implemented in STRUCTURE v.2.3.4 ${ }^{20}$ with ten runs of the admixture model, a burn-in period of 100,000 replications, a run length of 100,000 Markov Chain Monte Carlo (MCMC) iterations and the number of putative subpopulations $(K)$ ranging from one to ten. The optimum value of $K$ was selected based on the Delta $K$ estimate of Evanno et al. ${ }^{29}$ using Structure Harvester ${ }^{19}$. Accessions with a membership probability to a single subpopulation larger than $90 \%$ were considered genetically pure. Accessions with membership $\leq 90 \%$ to a single subpopulation were considered admixed. A principal coordinates analysis (PCoA) was performed using the same dataset with GenAlEx $6.502^{30}$.

\section{Genetic diversity and phylogenetic analysis based on SNP markers}

The number of effective alleles $(\mathrm{Ne})$, number of private SNPs, percentage of polymorphic loci $(P)$, Shannon's information index $(I)$, observed and expected heterozygosity (Ho, He) and fixation index (Fis) were calculated using GenAlEx $6.502^{30}$ and values were compared across the seven species. The overall genetic distance (Fst) and estimated gene flow $\left(N_{\mathrm{m}}\right)$ between species were also calculated in GenAlEx $6.502^{30}$. In addition, the correlation between genetic and geographic distance was analyzed across all accessions as well as within species using a Mantel test implemented in GenAlEx 6.502. Phylogenetic analyses using the Neighbor Joining (NJ) and Unweighted Pair Group Method with Arithmetic mean (UPGMA) methods, and a bootstrap test with 500 replications were performed with DARwin 6.0.14 software $^{31}$ to reveal relationships within the genus Eremurus. In addition, the pairwise Nei's genetic distance and Fst genetic differentiation were calculated between the seven species of the Eremurus genus using SNPs identified across species ('species SNPs') and between clades within the largest population groups using SNPs identified within subpopulations ('subpopulation SNPs') in GenAlEx 6.502.

To examine the power of the SNP markers to detect unique multilocus genotypes (MLGs), we generated genotype accumulation curves using the total 'species SNP' dataset (3002 SNPs) and random subsets of 100, 200, 500, and 1000 SNPs using the function 'genotype-curve' implemented in the R3.2.2 ${ }^{32}$ package 'ppopr'. The genotype-curve function randomly samples different subsets of SNPs without replacement and plots the relationship between the number of SNPs scored and the number of MLGs identified.

\section{Genetic diversity based on morphological characteristics}

The 16 morphological traits scored for species identification were compared for their Shannon-Weiner diversity index $\left(H^{\prime}\right)$ using the following formula: $H^{\prime}=-\sum p_{i} \ln$ $\left(p_{i}\right)$, where $p_{i}$ is the frequency of the $i$ th character. The 
morphological diversity of each species was estimated by calculating the $H^{\prime}$ diversity index, the number of morphotypes (number of different combinations of morphological characters), the number of private morphotypes (number of morphotypes present in a single species only), the number of private characters (characters fixed in one species at a frequency of $100 \%$ and absent in all other species) and diagnostic characters (characters present in one species at a frequency below $100 \%$ and absent in all other species). The number of total morphotypes and private morphotypes were also calculated by clade for the three largest subpopulation groups as determined by STRUCTURE. In addition, morphological differentiation within the genus Eremurus was investigated based on the 16 traits by a Principal Coordinates Analysis (PCoA) using GenAlEx $6.502^{30}$. The contribution of each morphological trait to axes 1 and 2 was calculated using the R3.2.2 $2^{32}$ packages 'FactoMineR' and 'Factoextra'. Variability among species and within species for morphological traits was assessed in GenAlEx $6.502^{30}$. Finally, a Mantel test was performed between the genetic and morphological matrix distances across the genotyped accessions using GenAlEx 6.502.

\section{Acknowledgements}

The research was supported by a research fund of Tarbiat Modares University, Iran and the University of Georgia, USA. This work represents partial fulfillment of the requirement for obtaining a Ph.D. degree by Hanieh Hadizadeh from Tarbiat Modares University. H.H. acknowledges the professional guidance and support of Alireza Babaei, Leila Samiei and Alireza Seifi during her PhD research.

\section{Author details}

'Department of Horticulture, Faculty of Agriculture, Tarbiat Modares University, Tehran, Iran. ${ }^{2}$ Laboratory of Bioaggressors and Integrated Protection in Agriculture, The National Agronomic Institute of Tunisia, University of Carthage, 1082 Tunis, Tunisia. ${ }^{3}$ Institute of Plant Breeding, Genetics and Genomics (Department of Crop and Soil Sciences), and Department of Plant Biology, University of Georgia, Athens, GA 30602, USA. ${ }^{4}$ Institute of Plant Breeding, Genetics and Genomics (Department of Horticulture), University of Georgia, Athens, GA 30602, USA. ${ }^{5}$ Present address: Department of Plant Pathology, University of Georgia, Griffin, GA 30223, USA

\section{Author contributions}

H.H., H.D.W., and K.M.D. conceived the project, H.H. did the collections and morphological identification, P.Q. conducted the GBS analysis and B.A.B. conducted the population genetic analyses. K.M.D. and D.W. wrote the paper, and all authors revised and approved the paper.

\section{Data availability}

Raw GBS reads have been submitted to NCBI's short read archive (SRA) (PRJNA544250). All SNPs used in the analyses, together with flanking sequence, and the genotypic scores for all accessions have been included as supplementary information. All other relevant information is included as tables, figures, or supplementary information.

\section{Conflict of interest}

The authors declare that they have no conflict of interest.

Supplementary Information accompanies this paper at (https://doi.org/ 10.1038/s41438-020-0265-9).
Received: 29 August 2019 Revised: 8 February 2020 Accepted: 12 February 2020

Published online: 02 March 2020

\section{References}

1. Wendelbo, P. Further notes on Eremurus (Liliaceae) in Afghanistan. Acta Hortic. Gotobg. 28, 57-63 (1966).

2. Kamenetsky, R. \& Rabinowitch, E. Flowering response of Eremurus to postharvest temperatures. Sci. Hortic. 79, 75-86 (1999).

3. Gaggeri, R. et al. Towards elucidating Eremurus root remedy: chemical profiling and preliminary biological investigations of Eremurus persicus and Eremurus spectabilis root ethanolic extracts. J. Med. Plants Res. 9, 1038-1048 (2015).

4. Tuzcu, Z. et al. Antioxidant, antimicrobial and anticancer effects of different extracts from wild edible plant Eremurus spectabilis leaves and roots. Int J. Clin. Exp. Med. 10, 4787-4797 (2017).

5. Rossi, D. et al. (R)-(-)-Aloesaponol III 8-methyl ether from Eremurus persicus: a novel compound against Leishmaniosis. Molecules 22, 519 (2017).

6. Aysu, T., Demirbaş, A., Bengü, A. Ş. \& Küçük, M. M. Evaluation of Eremurus spectabilis for production of bio-oils with supercritical solvents. Process Saf. Environ. 94, 339-349 (2015).

7. Eghtedarnejad, N. Building wooden panels glued with a combination of natural adhesive of tannin/Eremurus root (syrysh). Eur. J. Wood Wood Prod. 74, 269-272 (2016).

8. Naderi Safar, K., Kazempour Osaloo, S., Assadi, M., Zarrei, M. \& Khoshsokhan Mozaffar, M. Phylogenetic analysis of Eremurus, Asphodelus, and Asphodeline (Xanthorrhoeaceae-Asphodeloideae) inferred from plastid trnL-F and nrDNA ITS sequences. Biochem Syst. Ecol. 56, 32-39 (2014).

9. Baird, N. A. et al. Rapid SNP discovery and genetic mapping using sequenced RAD markers. PLOS ONE 3, e3376 (2008).

10. Elshire, R. J. et al. A robust, simple genotyping-by-sequencing (GBS) approach for high diversity species. PLOS ONE 6, e19379 (2011).

11. Qi, P. et al. UGbS-Flex, a novel bioinformatics pipeline for imputation-free SNP discovery in polyploids without a reference genome: finger millet as a case study. BMC Plant Biol. 18, 117 (2018).

12. Cheng, L. \& Zhang, Y. J. Chromosome number and karyotype of Eremurus chinensis Fedtsch. J. Wuhan. Bot. Res. 11, 281-282 (1993).

13. Ling, W., Lingji, W., Miao, M. \& Aijun, Q. Karyotype analysis of Eremurus anisopterus. J. Shihezi Univ. 22, 417-418 (2004).

14. Smarda, P. et al. Ecological and evolutionary significance of genomic GC content diversity in monocots. Proc. Natl Acad. Sci. USA 11, E4096-E4102 (2014).

15. Wendelbo, P. Asphodeloideae: Asphodelus, Asphodeline \& Eremerus. Flora Iran. 151, 3-31 (1982).

16. Jalili, A. \& Jamzad, Z. Red Data Book of Iran: A Preliminary Survey of Endemic Rare and Endangered Plant Sepcies in Iran. (Research Inst of Forests and Rangelands, Tehran, Iran, 1999).

17. Fan, J. \& Ma, M. A study on the pollination ecology of Eremurus inderiensis. J. Sustain Dev. 1, 133-137 (2008).

18. Ma, M., Fan, J. \& Li, J. Pollination characteristics of the ephemeroid plant Eremurus anisopterus. Front Biol. 3, 315-319 (2008).

19. Earl, D. A. \& vonHoldt, B. M. STRUCTURE HARVESTER: a website and program for visualizing STRUCTURE output and implementing the Evanno method. Consen. Genet. Resour. 4, 359-361 (2012).

20. Pritchard, J. K., Stephens, M. \& Donnelly, P. Inference of population structure using multilocus genotype data. Genetics 155, 945-959 (2000).

21. Berthouly-Salazar, C. et al. Genotyping-by-sequencing SNP identification for crops without a reference genome: using transcriptome based mapping as an alternative strategy. Front Plant Sci. 7, 777 (2016).

22. Melo, A. T. O., Guthrie, R. S. \& Hale, I. GBS-based deconvolution of the surviving North American collection of cold-hardy kiwifruit (Actinidia spp.) germplasm. PLOS ONE 12, e0170580 (2017).

23. Poland, J. A., Brown, P. J., Sorrells, M. E. \& Jannink, J.-L. Development of highdensity genetic maps for barley and wheat using a novel two-enzyme genotyping-by-sequencing approach. PLOS ONE 7, e32253 (2012).

24. Catchen, J. M., Amores, A., Hohenlohe, P., Cresko, W. \& Postlethwait, J. H. Stacks: building and genotyping loci de novo from short-read sequences. G3-Genes Genom. Genet. 1, 171-182 (2011).

25. Baker, J. G. Revision of the genera and species of Anthericeae and Eriospermeae. Bot. J. Linn. Soc. 15, 253-363 (1876). 
26. Doyle, J. J. \& Doyle, J. L. Isolation of plant DNA from fresh tissue. Focus $\mathbf{1 2}$ 13-15 (1990).

27. Langmead, B. \& Salzberg, S. L. Fast gapped-read alignment with Bowtie 2. Nat. Methods 9, 357-359 (2012)

28. DePristo, M. A. et al. A framework for variation discovery and genotyping using next-generation DNA sequencing data. Nat. Genet. 43, 491-498 (2011).

29. Evanno, G., Regnaut, S. \& Goudet, J. Detecting the number of clusters of individuals using the software structure: a simulation study. Mol. Ecol. 14 2611-2620 (2005).
30. Peakall, R. \& Smouse, P. E. GenAlEx 6.5: genetic analysis in Excel. Population genetic software for teaching and research —an update. Bioinformatics $\mathbf{2 8}$, 2537-2539 (2012).

31. Perrier, X. \& Jacquemoud-Collet, J. P. DARwin software. http://darwin.cirad.fr. (2006).

32. R Development Core Team. R: A Language and Environment for Statistical Computing (R Foundation for Statistical Computing, 2012). 